\title{
Restricted Expression of Measles Virus in Primary Rat Astroglial Cells
}

\author{
Sibylle Schneider-Schaulies, Uwe G. Liebert, K. Baczko, and V. ter Meulen'
}

Institut für Virologie und Immunbiologie, Universität Würzburg, Versbacher Strasse 7, D-8700 Würzburg, Federal Republic of Germany

Received January 10, 1990; accepted April 17, 1990

\begin{abstract}
Persistent infection of the central nervous system (CNS) with measles virus (MV) is associated with characteristic restrictions of viral envelope gene expression as documented in subacute sclerosing panencephalitis (SSPE), measles inclusion body encephalitis (MIBE), or subacute measles encephalitis (SAME) in rats. To determine whether these restrictions are the result of a long lasting virus-host cell interaction or primarily based on intrinsic brain cell factors MV gene expression was analyzed in primary rat astroglial cultures. It could be shown that MV infection of these cells led to a defective replication cycle with a reduced synthesis of viral envelope proteins and a steep expression gradient of the monocistronic viral mRNAs similar to the findings in brain tissue of SSPE, MIBE, and SAME. This restriction of MV gene expression has not been observed in cells of nonneural origin. We suggest that this cell-type specific regulation of MV gene expression contributes to early events in the establishment of MV persistent infection in CNS tissue. (1) 1990 Academic Press, Inc.
\end{abstract}

Measles virus infection in man may lead to chronic CNS diseases such as subacute sclerosing panencephalitis (SSPE) and measles inclusion body encephalitis (MIBE) $(1,2)$. These CNS disorders develop months or years after acute measles on the basis of a persistent MV infection in neurons and glial cells. Recently, molecular biological studies characterizing the state of MV persistence in brain tissue obtained at autopsy revealed a restriction of $\mathrm{MV}$ envelope genes as a result of transcriptional and translational defects (3-5). Some of these defects could be explained by mutations of MV genes which were seen in several of the cases studied (6). In addition, experimental infection of Lewis rats with a neurotropic strain of MV have shown in both acute (AE) and subacute encephalitis (SAME) after only short incubation periods the presence of molecular biological changes similar to those seen in SSPE or MIBE $(7,8)$. Obviously, the long lasting MV persistence is not required for the development of a restriction of MV gene expression. Moreover, it has been observed that antiviral antibodies either passively transferred to MV-infected newborn rats or developing in the course of MV infection in older rats also have a profound inhibitory effect on MV replication in brain tissue indicating a complex interaction between virus and host cell in the establishment of a CNS infection (9).

These findings led us to analyze $\mathrm{MV}$ replication in rat brain cell cultures in order to determine whether restrictions of MV gene expression occur only during infection in an intact host or also in tissue culture medi-

\footnotetext{
' To whom requests for reprints should be addressed.
}

ated by the activity of intrinsic cellular factors. For this purpose we used primary astroglial cell cultures from newborn Lewis rats as previously described (10), that stained for GFAP (>95\%) and for the type 1 astrocytespecific antigen Ran2 (89-93\%) and for A2B5-type 2 astrocyte-specific antigen (8-11\%) as determined by indirect immunofluorescence of monolayer cultures or by cytofluorographic (FACScan) analysis of trypsinized cells. Contamination by other cell types expressing Fc receptors, neurofilaments, and galactocerebroside was in the order of $5 \%$. Following infection of such cultures with different input multiplicities (m.o.i. ranging from 0.1 to 5) with either the neurotropic rat brainadapted CAM/RBH (11) or the nonneurotropic Edmon. ston strain of MV, only $30 \%$ of the cells were infectable as demonstrated by immunofluorescence $24 \mathrm{hr}$ p.i. (postinfection) (Table 1). The number of infected cells decreased to $10 \%$ by Day 3 p.i., and to about $5 \%$ by Day 6 p.i. The yield of infectious virus was very low ranging from 0.01 to $0.001 \mathrm{PFU}$ per infected cell 24 to $48 \mathrm{hr}$ p.i., respectively. Only slightly higher amounts of cell-associated virus could be rescued by cocultivation with Vero cells (data not shown). In contrast to MV-infected Vero cells, which are highly permissive for MV and produce up to 5-10 PFU/infected cell (data not shown), no cell fusion or giant cell formation could be detected in the infected astroglial cultures.

The expression of the individual MV structural proteins in relation to the $\mathrm{N}$ protein was investigated by applying a double immunofluorescent technique using mixtures of different monoclonal antibodies against $N$. $P, M, F$, and $H$ proteins as previously described (4). In 
TABLE 1

EXPRESSION OF MV PROTEINS IN PRIMARY INFECTED RAT Astroglial CULTURES

\begin{tabular}{rcccccccr}
\hline & $\begin{array}{c}\text { Infected } \\
\text { cells as } \\
\text { \% of } \\
\text { total } \\
\text { dpi }\end{array}$ & $\begin{array}{c}\text { No. of } \\
\text { cells } \\
\text { positive } \\
\text { for N } \\
\text { protein }\end{array}$ & \multicolumn{4}{c}{$\begin{array}{c}\text { \% infected cells with MV } \\
\text { structural proteins in relation } \\
\text { to N protein }\end{array}$} \\
\cline { 5 - 10 } 1 & 30 & 280 & 100 & 92 & 47 & 47 & 60 \\
2 & 25 & 340 & 100 & 94 & 10 & 21 & 48 \\
3 & 10 & 180 & 100 & 91 & 6 & 3 & 31 \\
6 & 5 & 100 & 100 & 85 & 0 & 0 & 13 \\
14 & 1 & 20 & 100 & 70 & 0 & 0 & 0 \\
\hline
\end{tabular}

Note. dpi indicates days postinfection.

Number of infected cells as detected with human anti-MV hyperimmune serum.

${ }^{b}$ Mixtures of three to five monoclonal antibodies (IgG isotypes) against the different structural proteins of MV were used as described (4)

the infected astroglial cultures $\mathrm{N}$ and $\mathrm{P}$ proteins were detectable in almost the same number of infected cells, whereas the expression of the envelope proteins $M, F$, and $\mathrm{H}$ was only seen in about $50 \%$ of the infected cells $24 \mathrm{hr}$ p.i. (Table 1). With increasing time p.i. the percentage of cells revealing a positive staining for $F$ and $M$ proteins was drastically reduced and at Day 6 p.i. these proteins were no longer detectable. The relative frequency of infected cells expressing the $\mathrm{H}$ protein was generally higher than for $M$ and $F$ protein and a small number of the infected astroglial cells (13\%) still stained for $\mathrm{H}$ protein at Day 6 (Table 1). By Day 14 , only $\mathrm{N}$ and $\mathrm{P}$ proteins could be detected. In control cultures of infected Vero cells, all of these MV structural proteins were detectable in each of the infected cells.

The occurrence of restricted MV gene expression in the infected astroglial cultures within $24 \mathrm{hr}$ p.i. suggested a regulation of viral replication by a host cellspecific factor(s). Therefore, synthesis and stability of MV structural proteins were assessed by pulse labeling EDM-MV-infected Vero cell and astroglial cultures with $\left[{ }^{35}\right.$ S]methionine $48 \mathrm{hr}$ p.i. as described previously $(12,13)$. Immediately after labeling, $H, P, N, F_{1}$, and $M$ protein and cellular actin could be precipitated from the lysates obtained from both infected cell systems (Fig. 1). In lysates from infected Vero cells, all of these MVspecific proteins except the $F_{1}$ and $M$ were still detectable after a chase period of $24 \mathrm{hr}$ (Fig. 1a, lane 7). In lysates from EDM-MV-infected astroglial cultures the signal intensities for all MV structural proteins were lower than in lysates from Vero cells. A decrease in signal intensity for the $N$ and $M$ protein could be seen after
$5 \mathrm{hr}$ of chase (Fig. $1 \mathrm{~b}$, lane 6 ) whereas $\mathrm{H}$ and $\mathrm{P}$ protein appeared to be more stable and were still visible after a 24-hr chase (Fig. 1b, lane 8). The higher stability of the $\mathrm{H}$ protein could probably explain the finding that infected astroglial cells express $H$ protein up to 6 days p.i. (Table 1). Analogous results were seen with the CAM/RBH strain of MV (data not shown). The electrophoretic mobility of MV structural proteins synthesized in the astroglial and Vero cell cultures were similar (Fig. 1). Since we had no evidence for a decreased stability of $\mathrm{MV}$ envelope proteins as an explanation for their failure to be detected in vivo, the transcription of MV-specific polyadenylated (+pA) RNAs was analyzed in EDMand CAM/RBH-infected astroglial cultures. Total RNA was extracted at $48 \mathrm{hrp}$.i., + pA selected, and analyzed by Northern blots using strand-specific RNA probes specific for the N-, P-, M-, F-, and H-mRNA as described previously (8). In order to quantify the signals obtained, a mixture of standard RNAs was included in each experiment (14) (Fig. 2). In samples derived either from CAM/RBH (Fig. 2b)- or EDM-infected (Fig. 2c) astroglial cultures at $48 \mathrm{hr}$ p.i., a significantly steeper expression gradient than in the control Vero cell-derived RNA (Fig. 2a) was observed with an attenuation of transcriptional efficiency starting at the $P$ gene and affecting particularly the mRNAs for the envelope genes $M$, $F$, and $\mathrm{H}$. In + pA-RNA isolated from CAM/RBH-infected astroglial cells an F-specific transcript migrating faster than the monocistronic mRNA appeared (Fig. 2b, lane $4, X$ band). This transcript could not be detected in noninfected or EDM-infected astroglial cells nor in CAM/ $\mathrm{RBH}$ - or EDM-infected Vero cells. In addition, a higher percentage of polycistronic transcripts compared to the lytic infection was visible. A quantitative analysis of the Northern blots revealed that the expression of the $\mathrm{N}$ gene was severely reduced in the astroglial cultures to a level of 1.6 and $3 \%$ of the Vero cell control (Table 2). The relative expression of the structural genes in relation to the $\mathrm{N}$ gene (expression of the $\mathrm{N}$ gene is set to $100 \%$ ) was reduced to 39 and $43 \%$ for the $\mathrm{P}$ gene (control: $78 \%$ ), to 29 and $30 \%$ for the $\mathrm{M}$ gene (control: $56 \%$ ), and 14 and $18 \%$ for the $F$ gene (control: $42 \%$ ). Due to the low signal intensity, exact quantification of the H-mRNA-specific signals from astroglial cultures was not possible. The biological activity of the envelope protein-specific mRNAs could not be tested in our in vitro translation system due to the low concentration of these RNAs. However, translational modification as an explanation for the lack of viral envelope proteins seems rather unlikely since the corresponding proteins were expressed within $24 \mathrm{hr}$ in approximately $50 \%$ of the infected astroglial cells (Table 1) and their synthesis could be detected $48 \mathrm{hr}$ p.i. (Fig. 1b). Hypermutational 
a.

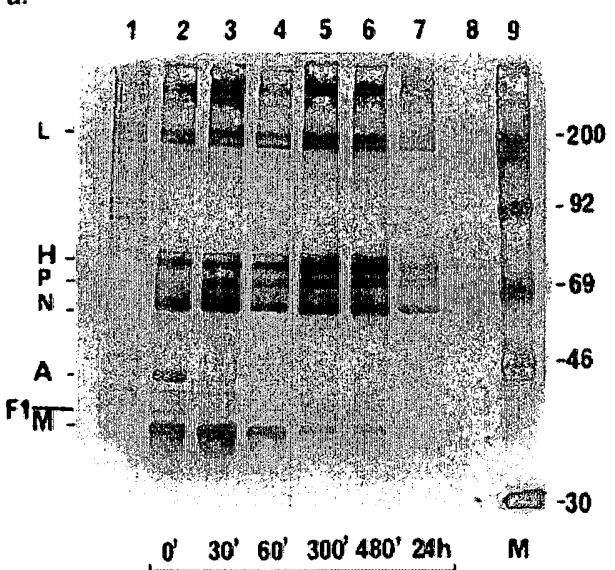

b.

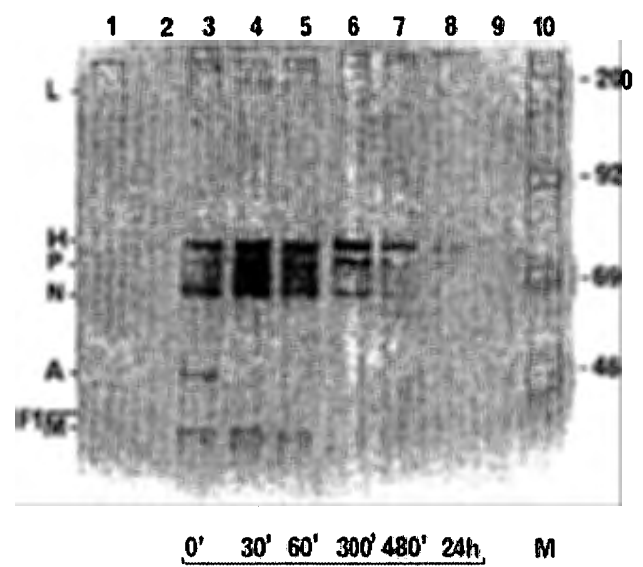

FIG. 1. Synthesis and stability of MV structural proteins in EDM-infected Vero cells and astroglial cells. Confluent monolayers were infected at a m.o.i. of $1,48 \mathrm{hr}$ later pulse labeled with $\left.{ }^{35} \mathrm{~S}\right]$ methionine $(300 \mu \mathrm{Ci} / \mathrm{ml} / 90 \mathrm{~min})$, and subsequently chased for the time intervals indicated. Equal amounts of protein from each lysate were immunoprecipitated by using a rabbit anti MV-hyperimmune serum. The lysate from EDMinfected Vero cells was diluted 1:3 with lysate from noninfected Vero cells to yield an equivalent percentage of infected cells compared to the astroglial cultures (b). Precipitates were subjected to electrophoresis on an $12.5 \%$ polyacrylamide gel. Lane 1 of a and b: precipitation of control lysate from uninfected cultures. Lanes 2-7 (a) and 3-8 (b): precipitation of lysates from infected Vero cells (a) and astroglial cells (b) prepared after the chase intervals indicated at the bottom of each panel. Lanes 8 (a), 2, and 9 (b) represent buffer controls.

events as a mechanism for translational defects as recently described for MV M gene $(6,15)$ cannot be ruled out. The reproducibility of the restrictions observed in several independent experiments and the general effect on the expression of all envelope proteins, however, strongly argue against hypermutational events as described.
The finding of transcriptional alterations together with a highly restricted expression of the viral envelope proteins in astroglial cells is very similar to the findings in persistent MV infection of brain tissue in man and rats $(3-5,8)$. The short time course for the development of the restrictions indicates that host cell-specific factors may play a role. This interpretation is supported

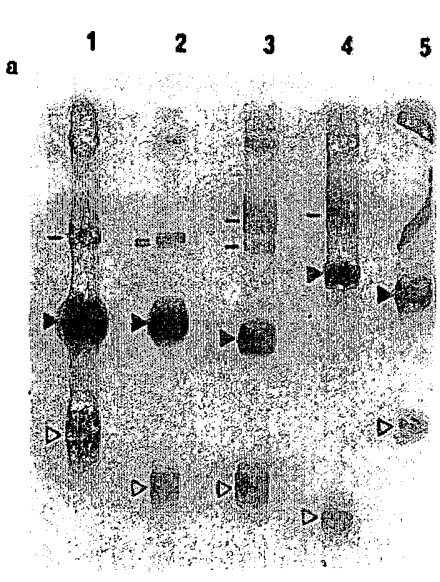

$\mathbf{N}$

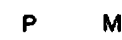

F $\quad H$
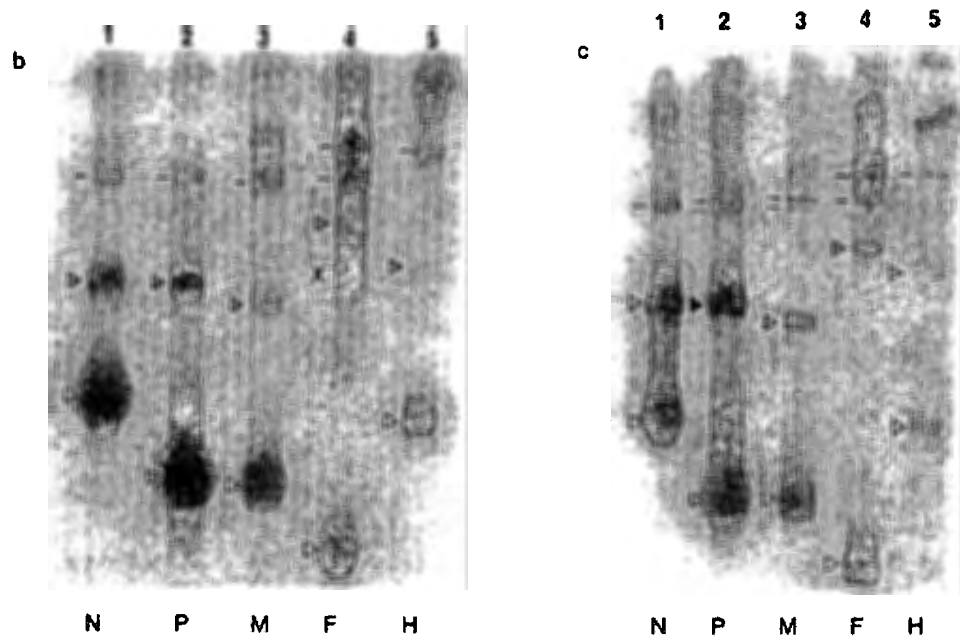

Fig. 2. Northern blot analysis of $1 \mu \mathrm{g}+\mathrm{pA}$ RNA from EDM-infected Vero cells (a), and CAM/RBH (b) or EDM-infected astroglial cells (c) 48 hr p.i. RNA samples were separated on a $1.5 \%$ formaldehyde-containing agarose gel and hybridization was performed as described previously ( 8 ) using [ $\left.{ }^{32} \mathrm{P}\right] \mathrm{CTP}$-labeled RNA probes specific for the N, P, M, F, and $\mathrm{H}$ gene (14). The open triangles indicate the position of the synthetic standard RNA transcripts (14) (2000 copies for N, P, M, and F and 400 for $\mathrm{H}$ ) in each lane; the solid black triangles, the position of the monocistronic mRNA transcripts; and the bars, the postion of the polycistronic transcripts. The $x$-labeled signal in lane 4 (b) marks the shorter F-specific transcript. 
TABLE 2

Quantitative Analysis of THe Transcription of MV-SPECIFIC Monocistronic mRNAs in Brain Cell Cultures and Vero Cells

\begin{tabular}{|c|c|c|c|c|c|c|}
\hline & \multirow{2}{*}{\multicolumn{2}{|c|}{$\begin{array}{l}\text { Vero cells } \\
\text { EDM } 48 \mathrm{hr}\end{array}$}} & \multicolumn{4}{|c|}{ MV-infected astrocyte cultures } \\
\hline & & & \multicolumn{2}{|c|}{ CAM/RBH $48 \mathrm{hr}$} & \multicolumn{2}{|c|}{ EDM $48 \mathrm{hr}$} \\
\hline & $c$ & $\%$ & $c$ & $\%$ & $c$ & $\%$ \\
\hline N & 19,800 & 100 & 319 & 100 & 601 & 100 \\
\hline $\mathrm{P}$ & 15,500 & 78 & 126 & 39 & 257 & 43 \\
\hline$M$ & 11.000 & 56 & 97 & 30 & 177 & 29 \\
\hline $\mathrm{F}$ & 8,400 & 42 & 56 & 18 & 85 & 14 \\
\hline $\mathrm{H}$ & 6,300 & 32 & $(20)^{a}$ & $(9)^{a}$ & $(36)^{\theta}$ & $(6)^{e}$ \\
\hline
\end{tabular}

Note. Following autoradiography of the Northern blots shown in Fig. 2, signals for the monocistronic RNAs and the corresponding standard RNAs were excised from the nitrocellulose filters and radioactivity retained was determined by scintillation counting. Values obtained for the expression of the individual mRNAs were determined either as copy numbers per $10 \mathrm{pg}$ RNA (c) or as relative expression frequencies in relation to the $\mathrm{N}$ gene expression (\%) in each sample (expression of the N mRNA is set to $100 \%$ ) as previously described (8).

The brackets indicate that exact quantification of the corresponding signals was not possible due to their low signal intensities (Figs. $2 \mathrm{~b}$ and $2 \mathrm{c}$, lane 5$)$.

by the fact that extracellular factors interfering with viral gene expression in the intact organism such as antiviral antibodies (9) are absent from our tissue culture system. The presence of cytokines such as TNF $\alpha$ and IFN $\alpha / \beta$ that have recently been detected in the supernatant of NDV-infected primary astrocyte cultures (16) have not been found in the supernatant of the MV-infected astroglial cell cultures employed here (data not shown).

The target of cell type-specific restriction seems to be predominantly at the level of transcription of viral mRNAs. One mechanism for obtaining a steep expression gradient for polyadenylated subgenomic mRNAs could be the overproduction of nonpolyadenylated transcripts. However, we have not been able to show the presence of detectable amounts of nonpolyadenylated transcripts in the $-\mathrm{pA}$ fraction derived from the infected astroglial cultures (data not shown). A second possible mechanism, a decreased stability of the virusspecific transcripts in the brain cells, could not be studied, since primary astroglial cell cultures are not very susceptible to MV infection and attempts to label MVspecific transcripts in vivo sufficiently failed. However, since degradation products of the monocistronic mRNAs were not visible on the Northern blots, we feel that degradation may not play a major role unless it occurs so rapidly that intermediate degradation products cannot be detected (Fig. 2). The X band in Fig. $2 b$ which is rather distinct and specific may indicate a premature termination of transcription rather than degradation. Finally, the observed higher production of polycistronic instead of monocistronic transcripts in infected astroglial cells (Figs. $2 \mathrm{~b}$ and $2 \mathrm{c}$ ) would provide an alternative mechanism to regulate the amount of monocistronic transcripts. It is conceivable that the viral polymerase complex and its activity are the targets for the cell typespecific restriction. While the $L$ and $P$ protein in lysates from the infected astroglial culture (Fig. 1b) do not reveal gross differences in their electrophoretic mobility compared to the corresponding proteins synthesized in the Vero cell (Fig. 1a), post-translational modifications, however, could have occurred and influenced the activity of the complex in the initiation and elongation of MV transcripts as shown for VSV (17).

Indeed, it has been shown recently that host cell restrictions for the transcriptional activity do exist for the segmented negative strand La Crosse RNA virus (18). In this study it was shown that viral transcription was dependent on the presence of cellular protein synthesis in particular host cells. The characterization of cell type-specific factors regulating MV gene expression will provide important information for the understanding of the establishment and the reactivation of persistent infections in cells of the central nervous system. For further studies it will be necessary to analyze these aspects in permanent astroglial cell lines that are susceptible for MV infection.

\section{ACKNOWLEDGMENTS}

The authors are grateful to Susanne Hellmig and Sieglinde Löffler for their excellent technical assistance, to Prof. Dr. M. Billeter and Dr. R. Cattaneo for providing the cDNA clones and for helpful discussions, to Dr. Jonathon Sedgwick for critical reading, and to Helga Kriesinger and Christel Stoppe for typing the manuscript. This work was supported by the Deutsche Forschungsgemeinschaft.

\section{REFERENCES}

1. ter Meulen, V., Stephenson, J. R., and Kreth, H. W., In "Comprehensive Virology" (H. Fraenkel-Conrat and R. R. Wagner, Eds.), Vol. 18, pp. 105-159. Plenum, New York, 1983.

2. Johnson, K. P., Norrby, E., Swoveland, P., and Carrigan, D. R., Arch. Virol. 73, 255-262 (1982).

3. Baczko, K., Liebert, U. G., Billeter, M. A. , Cattaneo, R., Budka, H., and TER MEULEN, V.J. Virol. 59, 472-478 (1986).

4. Liebert, U. G., BACZKo, K., BUdKA, H., and ter MEUlEN, V., J. Gen. Virol. 67, 2435-2444 (1986).

5. Cattaneo, R., Rebmann, G., Baczko, K., ter Meulen, V., and Bil. LETER, M. A., Virology 160, 523-526 (1987).

6. Cattaneo, R., Schmid, A., Eschle, D., Baczko, K., ter Meulen, V., and BILLETER, M. A., Ce/l 55, 255-265 (1988)

7. LIEBERT, U. G., and ter MEULEN, V., J. Gen. Virol. 68, 1715-1722 (1987) 
8. Schneider-Schaulies, S., Liebert, U. G., Baczko, K., Cattaneo, R., BILleter, M. A., and TER MEULEN, V., Virology 171, 525534 (1989).

9. Liebert, U. G., Schneider-Schaulies, S., and ter Meulen, V., J. Virol. 64, 706-713 (1990)

10. Massa, P. T., ter Meulen, V., and Fontana, A., Proc. Natl. Acad. Sci. USA 84, 4219-4223 (1987).

11. Kobune, K., Kobune, F., Yamanouchi, K., Nagashima, K., YoshimKAWA, Y., and HAYAMI, M., Japan. J. Exp. Med. 53, 177-180 (1983).

12. Sheppard, R. D., Raine, C. S., Bornstein, M. B., and Udem, S. A., Proc. Natl. Acad. Sci. USA 83, 7913-7917 (1986).
13. Ogura, H., Baczko, K., Rima, B. K., and ter Meulen, V., J. Virol. $61,472-479$ (1987).

14. Cattaneo, R., Rebmann, G., Schmid, A., Baczko, K., ter Meulen, V., and BilLLeter, M. A., EMBO J. 6(3), 681-688 (1987).

15. Wong, T. C., Ayata, M., Hirano, A., Yoshikawa, Y., Tsuruoka, H., and YamanOUCH, K., J. Virol. 63, 5464-5468 (1989).

16. Lieberman, A. P., Pitha, P. M., Shin, H. S., and Shin, M. L., Proc. Natl. Acad. Sci. USA 86, 6348-6352 (1989).

17. Baneruee, A. K., Microbiol. Rev. 51, 66-87 (1987).

18. RAUU, R., RAU, L., and KOLAKOFSKY, D., Virology 63, 5159-5165 (1989). 